\title{
An audit of diabetes self-management education programs in South Africa
}

\author{
Loveness Dube, ${ }^{1}$ Stephan Van den Broucke, ${ }^{1}$ William Dhoore, ${ }^{2}$ Kerry Kalweit, ${ }^{3}$ \\ Marie Housiaux ${ }^{1}$ \\ ${ }^{1}$ Psychological Sciences Research Institute, Université Catholique de Louvain, Louvain-la-Neuve, \\ Belgium; ${ }^{2}$ Institute of Health and Society, Université Catholique de Louvain, Brussels, Belgium; \\ ${ }^{3}$ School of Health Systems and Public Health, University of Pretoria, South Africa
}

Significance for public health

Diabetes significantly contributes to the global burden of disease. This burden is especially felt in developing countries, where resources are limited and the health system simultaneously has to deal with communicable and non-communicable diseases. While there is a growing body of literature on the development and implementation of diabetes self-management education, nearly all programs originate from developed countries. Very little is known about the current state of diabetes self-management education in developing countries. By focusing on diabetes self-management education in Southern Africa, the current paper provides policy makers and decision makers in South Africa with information that will help decide on where and how to intervene with regard to diabetes self-management education. The paper also has relevance for decision makers from other developing countries by providing recommendations on diabetes policies and diabetes selfmanagement education.

\section{Abstract}

Background: Diabetes is a significant contributor to the burden of disease worldwide. Since its treatment requires extensive self-care, self-management education is widely recommended, particularly in resource limited settings. This study aimed to review the current state of policies and implementation of diabetes self-management education (DSME) in South Africa, with a specific focus on cultural appropriateness.

Design and Methods: The audit involved a review of policy documents and semi-structured questionnaires with providers and experts in public and private health services. Forty-four respondents were interviewed. Documents were analysed with reference to the International Standards for Diabetes Education from the International Diabetes Federation. Data were entered and analysed in excel to give a description of the DSME programs and ad hoc interventions.

Results: Three guidelines for Type 2 diabetes and two for chronic diseases were retrieved, but none were specifically dedicated to DSME. Five structured programs and $22 \mathrm{ad}$-hoc interventions were identified. DSME is mostly provided by doctors, nurses and dieticians and not consistently linked to other initiatives such as support groups. Health education materials are mainly in English with limited availability.

Conclusions: DSME in South Africa is limited in scope, content and consistency, especially in the public services. A National curricula and materials for diabetes education need to be developed and adapted to the socio-economic context, culture and literacy levels of the target populations. It is recommended that DSME would be addressed in national policies and guidelines to guide the development and implementation of standardised programs.

\section{Introduction}

Diabetes mellitus (DM) is a significant contributor to the burden of disease worldwide, and its growing prevalence is a great concern for public health. ${ }^{1}$ Recent estimates indicate that 382 million people are living with diabetes worldwide, and that by the year 2035 this number will rise to 592 million. ${ }^{2}$ It is also estimated that about $77 \%$ of people with diabetes live in low- and middle-income countries where most deaths occur under the age of 60 years. ${ }^{2,3}$ As a result, many developing countries including South Africa are faced with the double burden of communicable and non-communicable diseases (NCDs). ${ }^{3}$

According to the International Diabetes Federation (IDF), there were nearly 3 million people with diabetes in South Africa in 2013, with a prevalence of $8.27 \%$ among the age group $20-79$ years. ${ }^{2}$ The rising prevalence of diabetes is largely due to economic development and urbanization which leads to changing lifestyles, thereby reducing physical activity and increasing the levels of obesity and the consumption of foods high in salt, fat and sugar. ${ }^{4}$ The prevalence of obesity is indeed very high in South Africa, where the rates of obesity and combined overweight and obesity ( $42 \%$ and $69.3 \%$, respectively) are the highest in Sub-Saharan Africa. ${ }^{5}$

As diabetes requires extensive self-management related to diet, exercise and medication in order to prevent complications, self-management education and support are regarded as a critical element of treatment for all people with diabetes. ${ }^{6}$ As such, diabetes self-management education (DSME) is widely recommended and carried out where resources permit. However, despite the great variety of DSME programs that are currently available internationally, there is a paucity of information regarding educational interventions for the prevention of diabetes complications in developing countries. ${ }^{7,8}$

The National Department of Health of South Africa has recently taken the initiative to re-engineer the organisation of Primary Health Care (PHC) in the country and to develop a National Health Insurance (NHI) system. ${ }^{9}$ A National Summit on the prevention and control of NCDs organized in 2011 resulted in the commitment to develop and implement different strategies to prevent and control NCDs through preventive, health promoting, curative, rehabilitative and palliative services at all levels. ${ }^{10}$ As such, it is important, to consider how DSME can be integrated in this new system, and to what extent the re-engineering of PHC provide a basis to develop and implement evidencebased programs for diabetes self-management.

Moreover, for DSME to be effective in a multicultural society like South Africa, it is required that both the educators and the content of programs be culturally sensitive. ${ }^{11}$ Cultural sensitivity can be considered at two levels: surface structure and deep structure. ${ }^{7}$ Surface structure refers to matching the intervention materials and messages to observable superficial characteristics of a target population, such as familiar people, places, language, music, food and locations. Deep 
structure requires an understanding of the cultural, social, historical and psychological forces that influence the target population.

This study sought to review the policies and guidelines presently available in South Africa with regard to DSME, and to characterise the existing DSME offered in both the private and the public health care services. The questions addressed in the audit were to establish what types of DSME programs are currently offered in different settings across the country, who implements them, what educational approaches are used, how the programs are structured, how accessible they are, what challenges are faced, and to what extent they are culturally sensitive. As such, the audit provides a snapshot of the current state of DSME policies and guidelines and of the implementation of DSME programs in South Africa.

\section{Design and Methods}

\section{Study design and setting}

An audit was conducted from March to June 2014 to explore DSME policies and programs across the seven Provinces of South Africa. The audit involved a document review of DSME policy and guidelines as well as interviews with health service providers and experts involved in diabetes service provision, management and research, in order to describe current DSME interventions.

\section{Definition of terms}

An intervention is referred to as a structured program when it has a clear definition, a specific target group, a planned structure, a clear objective, a defined timeframe, and a person/unit with formal program responsibility (Röthlin et al. Unpublished). For the purpose of this study, ad-hoc interventions were regarded as those interventions which include educational talks in the waiting area or spontaneous sharing of information during individual medical consultations without planned structure and defined time frame. A public health service is one that is provided by the national government, whereas a private health service is one provided by the private sector and is for profit making. Providers include nurses, doctors, health educators and experts refer to either researchers or people involved in the field of diabetes in government, universities or private services.

\section{Sampling}

Purposive, convenience and snowball sampling were used to select respondents aiming for diversity between public and private providers. Purposive sampling was used to include respondents from different health sectors, as differences were expected between private and public services. Convenience sampling was applied by asking the organisers of the 49th Congress of the Society for Endocrinology, Metabolism and Diabetes of South Africa (SEMDSA) the permission to recruit participants attending this congress. Furthermore, respondents were recruited from different settings, including selected public and private facilities and non-governmental organisations (NGO) using snowball sampling. The first author (LD) contacted Heads of the Provincial Health Departments of all provinces of South Africa and asked to be referred to a focal person for chronic diseases in each Province. Provincial focal persons were interviewed and referred the researchers to relevant facilities and other NGO focal people in the area. Data were only collected from Provinces who gave approval and from individuals who gave informed consent to participate.

\section{Data collection}

Policy and guideline documents for the review were accessed via the website of the National Department of Health. ${ }^{11}$ To avoid missing relevant documents, respondents were asked for any available documents and copies were collected if available. Only documents relating to Type 2 diabetes were included for document analysis.

For the data collection from service providers, experts and researchers, two questionnaires were used. The questionnaires were adapted from the Global Diabetes Survey (GDS), which is a tool to collect data on diabetes care quality on a yearly basis, developed and validated via a multiple Delphi process. ${ }^{12,13}$ The provider questionnaire collected information about existing DSME programs in terms of the type of programs, providers, target groups, educational approach, and challenges faced. The expert questionnaire collected information regarding DSME policy, accreditation of DSME interventions by accrediting bodies (standardising bodies) and suggestions for policies and guidelines. The questionnaires were mostly self-administered but in a few cases ( 5 interviews) they were interviewer administered. Additional notes were taken during the interviews.

\section{Data management and analysis}

Data from the documents were extracted using the International Standards for Diabetes Education (ISDE) developed by the International Diabetes Federation. These standards have been developed and revised based on experiences from diabetes educators in both developing and developed countries, and aim to support policy makers worldwide to develop diabetes education. They provide a benchmark against which the quality of education delivered can be evaluated. ${ }^{14}$ The ISDE were used by two authors (LD and MH) to independently extract information on the content of DSME in the national guidelines in order to establish the adequacy of these documents in South Africa in terms of structure, process and outcome standards. An agreement of $90 \%$ was achieved between the authors and through further discussion a consensus (100\% agreement) was reached. Questionnaire data were entered and analysed in excel to give an overview of the current status of DSME in private and public services of South Africa.

\section{Ethics}

The study was approved by the Health Sciences Research Ethics Committee of the University of Pretoria (54/2014) and the Provincial Research Ethics Committees of each province in the public sector. Respondents gave written informed consent and anonymity and confidentiality of their responses was assured.

\section{Results}

\section{Distribution of participants across provinces}

Forty-four respondents completed the questionnaires; 27 providers (7 from private, 4 from NG0s and 16 public) and 17 experts. Data was collected in all provinces except for Eastern Cape and Limpopo's public sector where no permission was granted. Table 1 shows number of respondents per province with Gauteng having the highest number of respondents.

\section{Policies and guidelines with regard to diabetes self- management education}

No policy documents were identified with regards to DSME specifically. Three guideline documents on Type 2 diabetes were found: The Updated Management of Type 2 Diabetes in Adults at Primary Care Level, released in 2014; ${ }^{15}$ The National Guidelines for the Management of Diabetes Type 1 and 2 in Adults at Hospital Level, released in 2005;16 and The 2012 SEMDSA Guideline for the Management of Type 2 Diabetes (Revised). ${ }^{17}$ The first two documents were obtained from the National 
Department of Health. In these three documents, diabetes education was minimally covered. The guidelines included information on structure and process standards; however, this information was not comprehensive. As shown in Table 2, it appears that the 2014 document from the National Department of Health was derived using the 2012 SEMDSA guidelines as the information included is almost the same. The 2005 document covered the least amount of information on DSME compared to the other two guidelines.

To understand DSME in the context of chronic disease management in South Africa, the Integrated Chronic Disease Management (ICDM) Manual (undated) ${ }^{18}$ and the Primary Care 101 guidelines were also taken into consideration. ${ }^{19}$ The ICDM is a model of care for chronic diseases that is being implemented by the National Department of Health of South Africa. The Primary care 101 is currently being implemented as part of the ICDM in primary care. The disease categories currently being addressed in this model are hypertension, diabetes, chronic obstructive pulmonary disease, asthma, epilepsy, mental health HIV/AIDS, tuberculosis (TB) and multi-drug resistant TB. The model contains a self-management component which aims to empower individuals to take responsibility for their illness through understanding the necessary preventive and promotional actions required to decrease complications and multiple visits to the facilities. The expected outcome is to create an informed, motivated and adherent patient.

According to this model, trained Community Health Workers (CHWs) are mandated to provide health education to patients during home visits. Health education and promotion strategies are applied at the individual, family and community level to reduce the risk factors for developing chronic diseases and prevent complications from the existing condition(s). The health education sessions include, but are not limited to: healthy eating, active living through appropriate exercises, decrease in alcohol intake, reduction in tobacco, snuff, alcohol, salt and risky sexual behaviour.

The primary care 101 guideline document is designed in such a way that for each chronic disease, ${ }^{19}$ it gives some educational information which the provider should give to the patient. For diabetes the provider is advised to encourage the patient to adhere to medication, educate patient on recognising and managing hypoglycaemia, and to care for their feet.

In their responses to the questionnaires, experts and providers made recommendations that could be included in policies and guidelines for implementation of DSME. These include environment related policies such as subsidization of healthy foods and support for people with diabetes in the work place. To support patient adherence to insulin use, policies could mandate patients to bring back an empty insulin pen to qualify for renewal of insulin prescription. Furthermore, guidelines could also include dietary recommendations appropriate for poor communities in order to support patients to adhere to dietary recommendations. Guidelines could consider more attention to the actual implementation of DSME, support for educational programs, establishment of one standard-assuring body for diabetes education and also consider recognition of the training of providers in DSME.

\section{Description of diabetes self-management education programs}

Of the 27 respondents who answered the questionnaire on interventions, 5 reported on structured programs and 22 reported on ad-hoc education interventions. Sixteen of the 27 programs are in the public services whilst 11 are in the private services and NGOs. Respondents reported that few interventions (37\%) are accredited by a professional body [Diabetes Education Society of South Africa (DESSA), the International Diabetes Federation (IDF), the United Kingdom Diabetes Association and Center for Diabetes Education (CDE), the Provincial Department of Health and SEMDSA].

Of the 5 programs that are structured, three are in the public servic- es and two in the private services. All the programs are offered as initial education interventions and have a clear start and an end with a duration of two days to eight months (Table 3). At two facilities the same program is offered. Twenty-two services offer ad-hoc education. Of these, 13 are in the public services and nine in the private sector. Most DSME interventions (15 of 22) are incorporated into the ICDM, whereby the diabetes patients are grouped with those with other chronic illnesses for educational purposes. This education mostly takes place in the facility waiting area or club rooms, or, in the case of individual counselling, sometimes during medical consultations with the providers. DSME interventions in the public sector are free of charge. In the private sector they are included in the consultation fee.

\section{Providers}

For both structured programs and ad-hoc education, different combinations of providers are employed. Most providers are health professionals, with physicians and dietitians being the most common. Health promoters are the only non-professional category mentioned (Figure 1). Respondents also mentioned that training is essential for providers and that specific diabetes-related training courses are necessary, including the ones provided by DESSA or CDE.

\section{Target population}

In structured programs, the target population are patients with either Type 1 or 2 diabetes and other chronic diseases. Only one program addressed children and adolescents with Type 1 diabetes. The $a d-$ hoc interventions in the public services mostly target adult patients, while children are referred to specific facilities. In the private service all age groups are addressed. Educational interventions offered in the private services also address gestational diabetes, while in the public service these patients are immediately referred to the special maternity care clinics. In both structured and ad-hoc interventions, education is designed for patients and their families or their peers. The majority of the $a d$-hoc interventions were done in community based primary care, diabetes special care and hospital settings. Of the structured programs, 3 were offered in community based primary care, one in diabetes special care, and one in a non-clinical setting.

\section{Program content}

Content analysis of the structured and ad-hoc interventions was done based on the self-care behaviour topics included in the American Association of Diabetes Education (AADE) ${ }^{20}$ (i.e., healthy eating, staying active, taking medication, monitoring of blood glucose, problem solving, reducing risks and living with diabetes). In both the structured programs and $a d-h o c$ interventions, the content of the educational

Table 1. Number of respondents from each province.

\begin{tabular}{lccc} 
Province & $\begin{array}{c}\text { Provider } \\
\text { questionnaire }\end{array}$ & $\begin{array}{c}\text { Expert } \\
\text { questionnaire }\end{array}$ & $\begin{array}{c}\text { Total } \\
\text { respondents }\end{array}$ \\
Gauteng & 8 & 9 & 17 \\
Mpumalanga & 4 & 1 & 5 \\
\hline North West & 3 & 1 & 4 \\
Northern Cape & 1 & 1 & 7 \\
\hline Free State & 3 & 1 & 4 \\
Western Cape & 4 & 0 & 5 \\
\hline KwaZulu Natal & 2 & 3 & 7 \\
Limpopo & 2 & 1 & 3 \\
\hline Eastern Cape & 0 & 0 & 0 \\
Total & 27 & 17 & 44 \\
\hline
\end{tabular}


activities varied considerably. Table 4 shows the different contents of education for both structured and $a d-h o c$ interventions. As this table shows, across programs healthy eating, physical activity and self-monitoring of blood glucose were most often addressed, while glucagon administrations, self-measurement of blood pressure and dealing with the legal aspects of the disease were least often addressed.

\section{Educational approaches}

In the structured programs, education is offered in planned group sessions with professional facilitation and sometimes with additional individual and self-help sessions for patients with poorly controlled diabetes. A structured written curriculum for each program is available and two of the programs use the I change 4 Health lifestyle change materials developed for patients with non-communicable diseases. ${ }^{21}$ One program has a website available for patients. The $a d$-hoc educational interventions are offered in groups in the waiting area and during individual consultation sessions with the provider. Some ad-hoc educational interventions had written guidelines to which provider could refer for information. Respondents reported using pamphlets and booklets which are mainly written in English. In most cases these materials are supplied by pharmaceutical companies free of charge but are not always available. According to the respondents (93\%) from both structured and $a d-h o c$ interventions, education is accessible to people with low levels of literacy through the use of the local language, practical demonstrations, pictures and visual aids and the encouragement of family involvement. However, deep structural aspects of culture including individual needs assessment are rarely addressed.

\section{Evaluations of programs}

Two of the five structured programs were based on a randomised controlled trial (RCT) that showed the program to be cost-effective in the South African context. ${ }^{22}$ Two other programs are in the process of being evaluated: one using a randomised controlled trial, and another using a retrospective observation study. The remaining program was never evaluated. None of the $a d-h o c$ educational interventions have ever been evaluated.

The experts' responses to the questionnaires revealed that core educational principles exist on paper, yet their implementation is not guaranteed. In terms of the perceived effectiveness of DSME programs, most experts gave a score between 5 to 7 on a scale of 1-10 (with 1 being not at all effective versus 10 being very effective), indicating an intermediate effectiveness. When asked to identify the aspects of DMSE that need improvement, the experts mentioned the need to develop structured patient education programs and a need to train personnel in chronic disease education. The introduction of chronic disease education in schools as part of a school lifestyle and wellness was also suggested.

In their response to questionnaires, providers identified a range of problems that affect the delivery of DSME. One problem concerned inadequate finances, which results in a shortage of staff, long working hours, and lack of time and space for patient education which leads to low prioritisation of DSME. A second problem is the lack of recognition for staff after diabetes training, and a shortage of teaching materials to give to patients. A third issue concerns the patients, who are said to be ignorant and non-compliant. Abuse of services and misconceptions surrounding diabetes regardless of patient education was also mentioned. A further problem is related to poverty and the difficulty patients have in adhering to diet recommendations due to food insecurity.

\section{Discussion}

This audit aimed to collect information on policies and the nature of existing DSME programs in South Africa. It was revealed that although there is currently no policy specific to DSME in South Africa, DSME is

\section{Type of providers in ad-hoc activities}

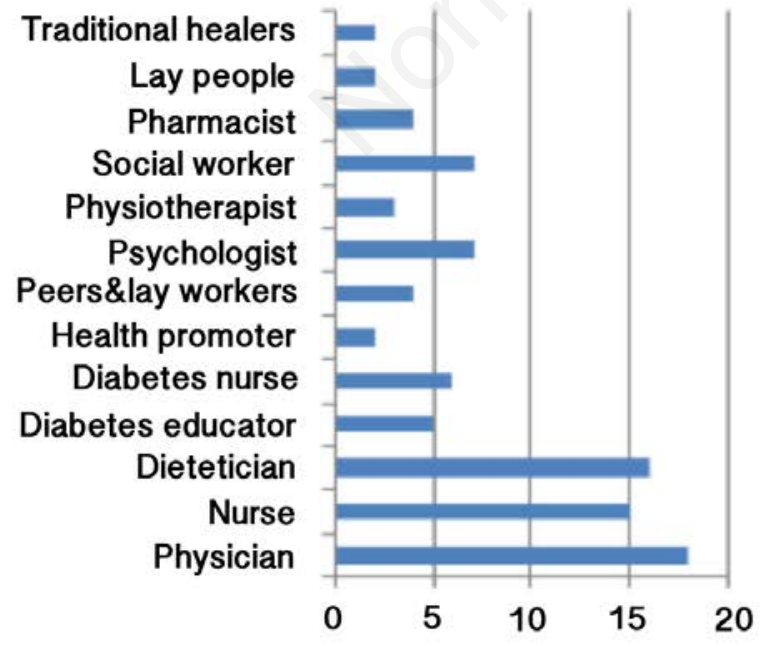

\section{Type of providers for structured programmes}

\section{Number of providers}

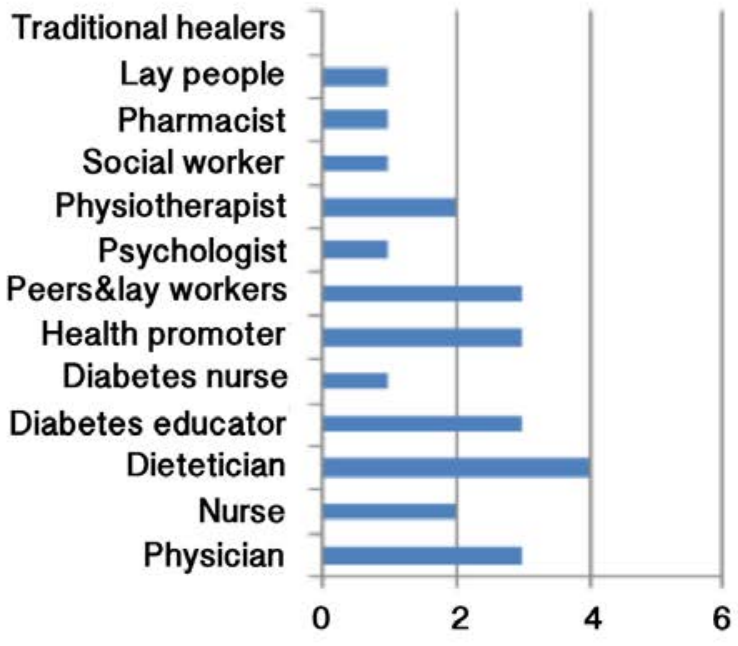

Figure 1. Type of providers in diabetes self-management education. 

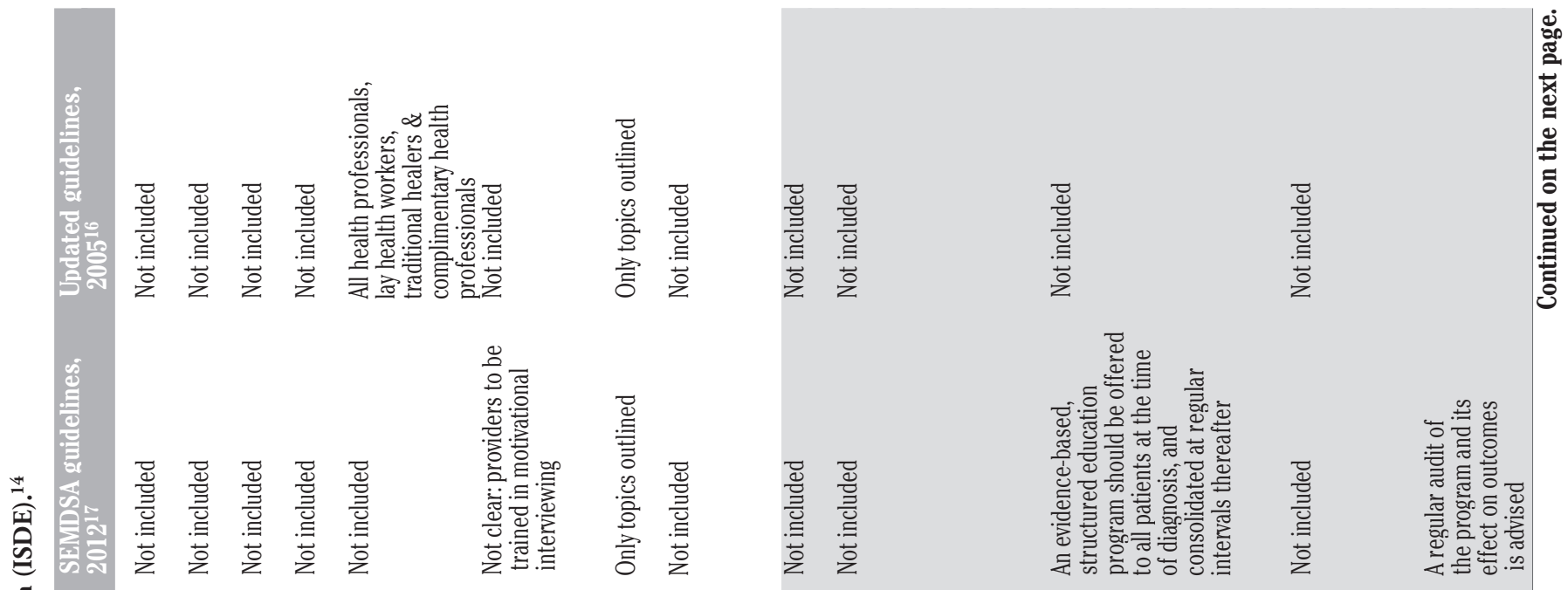

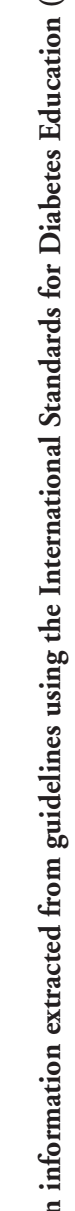

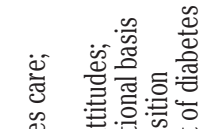

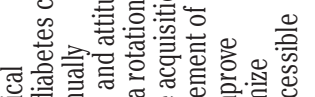

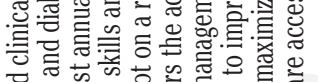

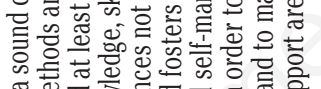

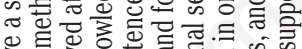

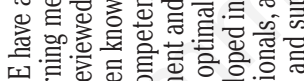

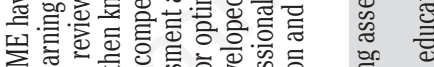

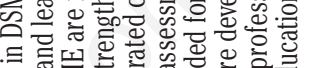

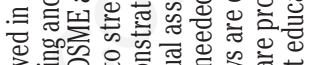
인.

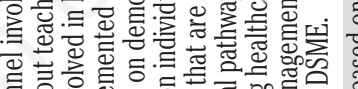

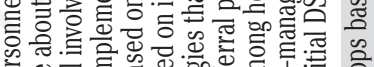

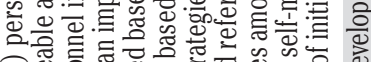
o.

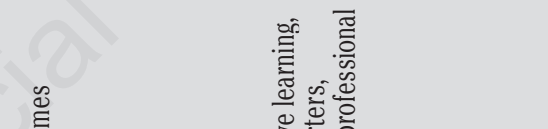

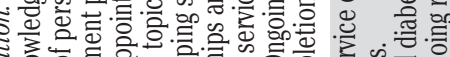

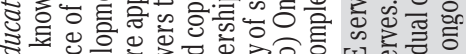

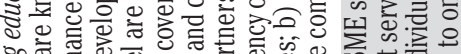

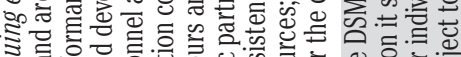

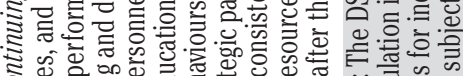

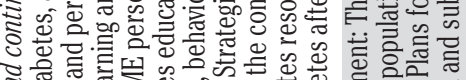

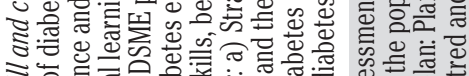

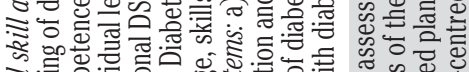

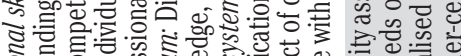

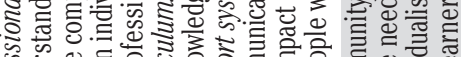

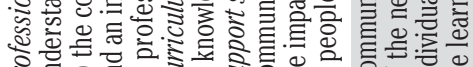

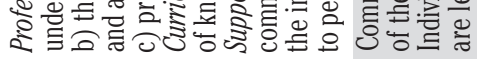

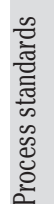

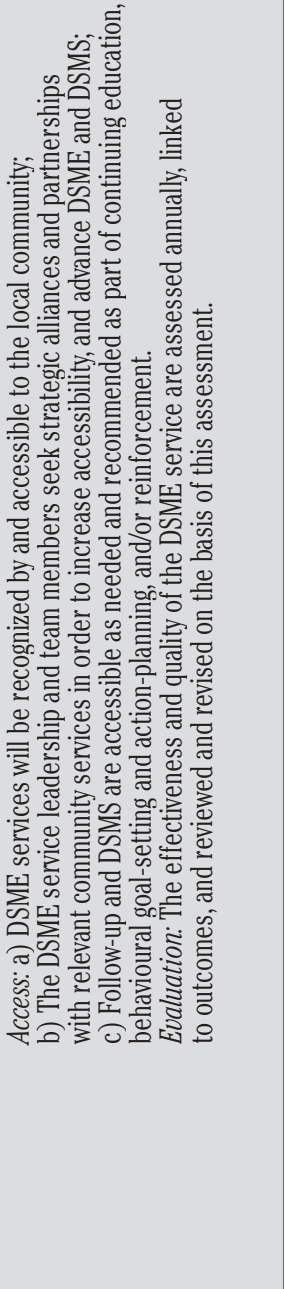




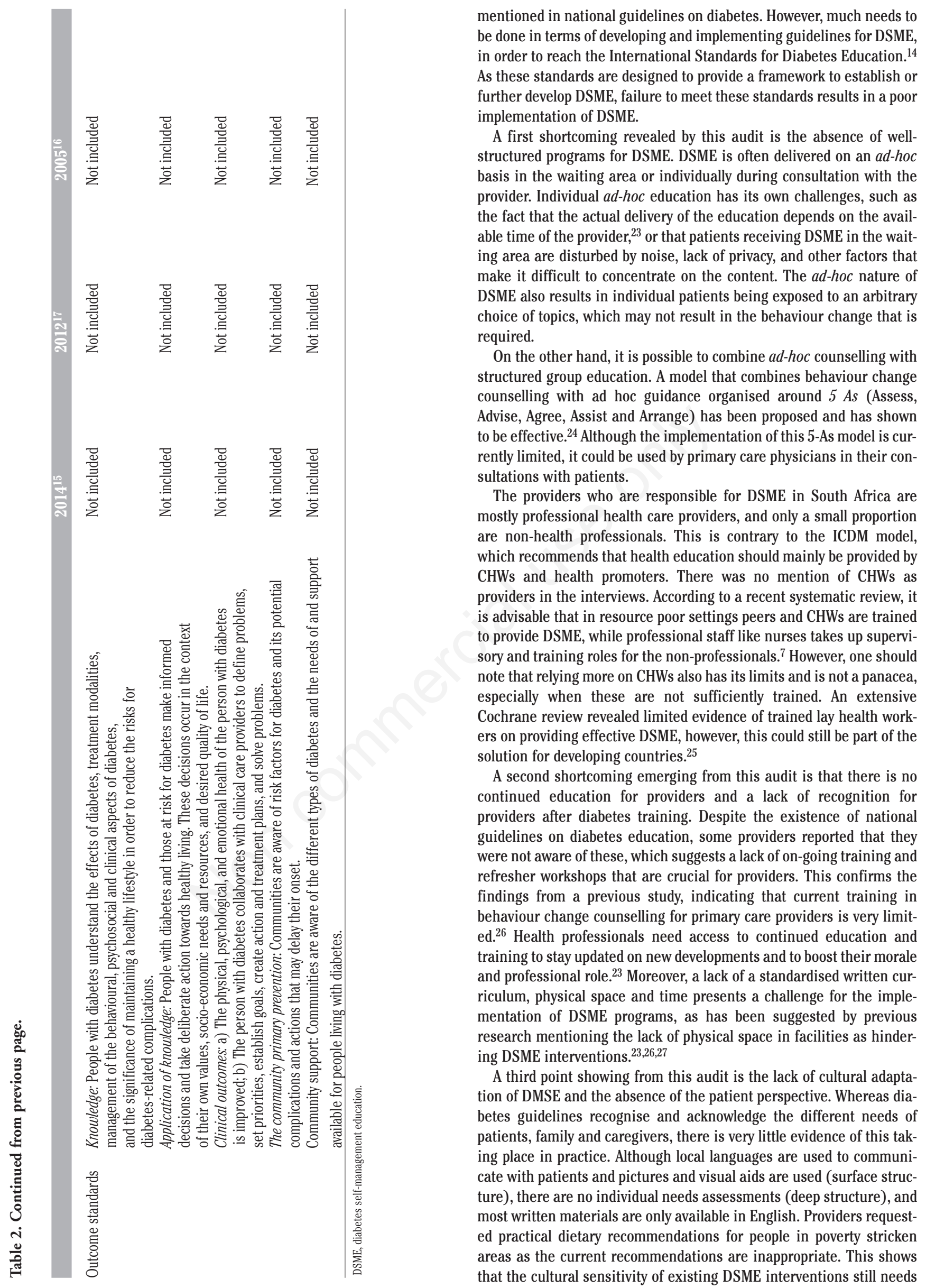


to be improved. For diabetes education to be effective in multicultural societies, both the educators and the content of programs should be culturally sensitive. ${ }^{7,8,28}$ Therefore, self-management curricula should be developed and adapted to the culture and needs of the patients. The patient education component in the Primary Care 101 document could be expanded in order to provide advice to providers.

A fourth shortcoming is the lack of evaluation of DSME programs. It is important in health promotion that programs be evaluated in order to contribute to the evidence base. ${ }^{29,30}$ Although the national guidelines on diabetes state that evidence-based structured self-management must be provided to patients and that a regular audit should be performed, this was not the case. Most DSME interventions, except for the two structured programs derived from the RCT, have not been evaluated, which makes it impossible to consider their effectiveness.

While this audit is the first of its kind to describe current policies and guidelines with regard to DSME in South Africa, and to consider the way in which DSME interventions are implemented in different settings across the country, we are aware of its limitations. Firstly, since non-randomised sampling was used as a method to select interventions for inclusion in the study, it is possible that we have missed some interventions. Furthermore, because of difficulty in obtaining ethical clearance from some facilities and authorities, and due to limited resources, some potentially relevant documents and interventions may have been missed. Thirdly no observation of interventions was carried out, which precludes the possibility of triangulating the results with what respondents reported. Nevertheless, given the recurrent findings and the high degree of consensus with regard to the information derived from the sources that were consulted, we believe that this audit provides a useful snapshot of the current policy and practice with regard to DSME in South Africa.

Table 3. Timeframes of structured programs.

\begin{tabular}{|c|c|c|c|c|}
\hline Name of program & Duration & Sessions, $\mathrm{n}$. & $\begin{array}{l}\text { Duration } \\
\text { of each session }\end{array}$ & $\begin{array}{l}\text { Period between } \\
\text { sessions }\end{array}$ \\
\hline Five steps to self-care (NGO-Gauteng) & 8 months & 32 & 30 min - 2 hours & 1 week \\
\hline $\begin{array}{l}\text { Diabetic Lifestyle Education Collaboration \& Action (D-LECA) } \\
\text { (Woodstock, public facility, Western Cape) }\end{array}$ & 4 months & 4 & 2-4hours & 1 month \\
\hline D-LECA (Lotus river, public facility, Western Cape) & 4 months & 4 & 1-2 hours & 1 month \\
\hline Lifestyle management + training for T2 diabetes (Public Hospital- Gauteng) & 6 weeks & 6 & 4 hours & 1 week \\
\hline Youth with diabetes weekend camps (Youth with Diabetes, NGO- Gauteng) & 2 days & 5 & $30-60$ minutes & Annual 2 days event \\
\hline
\end{tabular}

Table 4. Content included in programs and ad-hoc interventions.

\begin{tabular}{|c|c|c|c|}
\hline Topic based on AADE ${ }^{20}$ & Sub-topic & Ad-hoc & Structured \\
\hline Healthy eating & $\begin{array}{l}\text { Meal planning } \\
\text { Food labelling and interpretation } \\
\text { Weighing } \\
\text { Carbohydrates counting }\end{array}$ & $\begin{array}{l}21 \\
17 \\
16 \\
13\end{array}$ & $\begin{array}{l}4 \\
4 \\
4 \\
3\end{array}$ \\
\hline Physical activity & $\begin{array}{l}\text { Developing appropriate activity plans } \\
\text { Increase frequency, duration and intensity }\end{array}$ & $\begin{array}{l}21 \\
19\end{array}$ & $\begin{array}{l}2 \\
4\end{array}$ \\
\hline Self-monitoring of blood glucose & $\begin{array}{l}\text { Self-monitoring of blood glucose technique (skills) } \\
\text { Recording of blood glucose values } \\
\text { Equipment use and care }\end{array}$ & $\begin{array}{l}22 \\
21 \\
18\end{array}$ & $\begin{array}{l}5 \\
5 \\
3\end{array}$ \\
\hline Taking medication & $\begin{array}{l}\text { Preparation, technique and administration } \\
\text { Recognition, treatment \& prevention of low blood glucose } \\
\text { Safe handling and disposal of equipment } \\
\text { Dose adjustment }\end{array}$ & $\begin{array}{l}20 \\
20 \\
18 \\
16\end{array}$ & $\begin{array}{l}5 \\
5 \\
4 \\
3\end{array}$ \\
\hline Problem solving & $\begin{array}{l}\text { Hypoglycaemia treatment } \\
\text { Use of blood glucose data to determine appropriate actions } \\
\text { Glucagon administration }\end{array}$ & $\begin{array}{c}22 \\
21 \\
7\end{array}$ & $\begin{array}{l}5 \\
5 \\
2\end{array}$ \\
\hline Reducing risks & $\begin{array}{l}\text { Self-management of blood glucose (knowledge) } \\
\text { Smoking cessation } \\
\text { Maintaining personal records } \\
\text { Foot exam } \\
\text { Staying in contact with diabetes care professionals } \\
\text { Support in searching for further contact and help } \\
\text { Self-measurement of blood pressure }\end{array}$ & $\begin{array}{l}19 \\
20 \\
19 \\
19 \\
18 \\
14 \\
10\end{array}$ & $\begin{array}{l}5 \\
3 \\
4 \\
3 \\
4 \\
4 \\
2\end{array}$ \\
\hline Living with diabetes & $\begin{array}{l}\text { Goal setting/individual targets } \\
\text { Problem solving } \\
\text { Coping strategies } \\
\text { Action planning } \\
\text { Understanding own clinical picture } \\
\text { Self-efficacy } \\
\text { Dealing with depression } \\
\text { Dealing with legal aspects of the disease }\end{array}$ & $\begin{array}{l}21 \\
20 \\
18 \\
18 \\
19 \\
20 \\
15 \\
10\end{array}$ & $\begin{array}{l}4 \\
4 \\
4 \\
3 \\
2 \\
1 \\
1 \\
0\end{array}$ \\
\hline
\end{tabular}




\section{Conclusions}

Diabetes self-management education is rarely adequately addressed in national policies and guidelines in South Africa, and much work still needs to be done for DSME in the country to reach international standards. At present, DSME is mainly offered on an ad-hoc basis, and only a few structured programs exist. For both ad-hoc and structured interventions, health professionals are the main providers. Many barriers exist to develop and implement more structured DSME. These include, but are not limited to, lack of time and space, lack of finances, and lack of educational resources in other languages than English. It is recommended that these points would be addressed in national policies to guide the development and implementation of standardised, more culturally sensitive and more effective DSME programs.

Correspondence: Loveness Dube, Psychological Sciences Research Institute, Université Catholique de Louvain, 10 Place Cardinal Mercier, box L3.05.01, 1348 Louvain-la-Neuve, Belgium.

Tel.: +32.010 .478068 - Fax: +32.010 .473774 .

E-mail: loveness.dube@uclouvain.be

Key words: Diabetes; self-management education; programs; audit; South Africa.

Dedication: This work is dedicated to Kirstie Rendall-Mkosi, who started the research but unfortunately passed away.

Acknowledgements: The authors would like to thank the Universite catholique de Louvain Scholarships for Development for sponsoring Miss Dube and the University of Pretoria for the research assistant grant. Many thanks as well to the members of the Diabetes Literacy Project for critically reviewing this manuscript and the reviewers for the constructive comments that improved this paper.

Contributions: LD was the principal investigator who conceptualised and carried out the study; SVB and KRM supervised LD and were involved in conceptualisation, analysis and writing the manuscript; KK assisted LD in data collection, and writing the manuscript; WD and MH were involved in the analysis and writing the manuscript.

Conflict of interest: the authors declare no potential conflict of interest.

Received for publication: 2 June 2015.

Accepted for publication: 9 September 2015.

(C) Copyright L. Dube et al., 2015

Licensee PAGEPress, Italy

Journal of Public Health Research 2015;4:581

doi:10.4081/jphr.2015.581

This work is licensed under a Creative Commons Attribution NonCommercial 3.0 License (CC BY-NC 3.0).

\section{References}

1. Hjelm K, Mufunda E. Zimbabwean diabetics' beliefs about health and illness: an interview study. BMC Int Health Hum Rights 2010;10:7.

2. IDF Diabetes Atlas. Sixth edition. 2013. Available from: https://www.idf.org/sites/default/files/EN_6E_Atlas_Full_0.pdf.

3. Mayosi BM, Flisher AJ, Lalloo UG, et al. The burden of non-communicable diseases in South Africa. Lancet 2009;374:934-47.

4. Whiting DR, Guariguata L, Weil C, Shaw J. IDF diabetes atlas: global estimates of the prevalence of diabetes for 2011 and 2030. Diabetes Res Clin Pract 2011;94:311-21.

5. Ng M, Fleming T, Robinson M, et al. Global, regional, and national prevalence of overweight and obesity in children and adults during
1980-2013: a systematic analysis for the Global Burden of Disease Study 2013. Lancet 2014;384:766-81.

6. Schinckus L, Van den Broucke S, Housiaux M. Assessment of implementation fidelity in diabetes self-management education programs: a systematic review. Patient Educ Couns 2014;96:13-21.

7. Dube L, Van den Broucke S, Housiaux M, et al. Type 2 diabetes selfmanagement education programs in high and low mortality developing countries: a systematic review. Diabetes Educ 2015;41:69-85.

8. Ezenwaka C, Eckel J. Prevention of diabetes complications in developing countries: time to intensify self-management education. Arch Physiol Biochem 2011;117:251-3.

9. National Department of Health South Africa. National Health Insurance in South Africa: Policy Paper. Available from: http://www.gov.za/documents/national-health-insurance-southafrica-policy-paper. Accessed on July 2015

10. South African Declaration on the prevention and control of noncommunicable diseases. 2011. Available from: http://www.health.uct.ac.za/usr/health/research/groupings/cdia/do wnloads/SA_NCD_Declaration.pdf.

11. Policy Documents. Department of Health South Africa. 2014. Available from: http:/www.health.gov.za/policies.php. Accessed on: July 2014.

12. Schwarz PE, Gallein G, Ebermann D, et al. Global diabetes survey: an annual report on quality of diabetes care. Diabetes Res Clin Pract 2013;100:11-8.

13. Van den Broucke S, Van der Zanden G, Chang P, et al. Enhancing the effectiveness of diabetes self-management education: the diabetes literacy project. Horm Metabol Res 2014;46:933-8.

14. International Standards for Diabetes Education. 3rd ed. 2009. Available from: http://www.idf.org/files/idf_publications/international_standards_for_diabetes_education_EN/index.html. Accessed on: July 2014.

15. National Department of Health South Africa. Updated management of type 2 diabetes in adults at primary care level. 2014.

16. National Department of Health South Africa. Management of diabetes type 1 and 2 in adults at hospital level. 2005.

17. Amod A, Ascott-Evans BH, Berg GI, et al. The 2012 SEMDSA guideline for the management of type 2 diabetes (revised). JEMDSA 2012;17:S1-95.

18. Asmall S, Mahomed 0. Integrated chronic diseases management manual. National Department of Health of South Africa. Available from: http://www.kznhealth.gov.za/family/Integrated-chronic-disease-management-manual.pdf.

19. National Department of Health of South Africa. Primary care 101: symptom-based integrated care approach to the adult in primary care. 2013/14. Available from: https://www.idealclinic.org.za/docs/ guidelines/PC\%20101\%20Guideline\%20v2_\%202013\%2014.pdf

20. Mulcahy K, Maryniuk M, Peeples M, et al. Diabetes self-management education core outcomes measures. Diabetes Educ 2003;29:768-88.

21. Everett-Murphy K, Mash B, Malan Z. Helping people to change. The busy healthcare practitioners guide to providing brief behaviour change counselling on non-communicable diseases (NCD) lifestyle risk factors. CIDA; 2013. Available from: http://www.ichangeforhealth.co.za/wp-content/uploads/HELPING\%20PEOPLE\%20CHANGE\%20Manual72.pdf?iframe=true\&widt $\mathrm{h}=100 \% 25$ \&height $=100 \% 25$

22. Mash R, Kroukamp R, Gaziano T, Levitt N. Cost-effectiveness of a diabetes group education program delivered by health promoters with a guiding style in underserved communities in Cape Town, South Africa. Patient Educ Couns 2015;98:622-6.

23. Parker WA, Steyn NP, Levitt NS, Lombard CJ. Health promotion services for patients having non-comminicable diseases: feedback from patients and health care providers in Cape Town, South 
Africa. BMC Public Health 2012;12:503.

24. Mash R. The KM seedat memorial lecture: behaviour change counselling in the South African context. Transactions 2014;58:58-62.

25. Deakin T, McShane CE, Cade JE, Williams RD. Group based training for self-management strategies in people with type 2 diabetes mellitus. Cochrane Database Syst Rev 2005:CD003417.

26. Malan Z, Mash B, Everett-Murphy K. A situational analysis of training for behaviour change counselling for primary care providers, South Africa. Afr J Prim Health Care Fam Med 2015;7:e1-10.

27. Mash RJ, Rhode H, Zwarenstein M, et al. Effectiveness of a group diabetes education programme in under-served communities in South Africa: a pragmatic cluster randomized controlled trial. Diabet Med 2014;31:987-93.

28. Rawal LB, Tapp RJ, Williams ED, et al. Prevention of type 2 diabetes and its complications in developing countries: a review. Int $\mathrm{J}$ Behav Med 2012;19:121-33.

29. Green J. Heath promotion, $2^{\text {nd }}$ ed: planning and strategies. London: SAGE Publications Ltd; 2010.

30. Tones K, Tilford S. Health promotion, 3rd ed: effectiveness, efficiency sand equity. Cheltenham: Nelson Thornes Ltd; 2001. 